\title{
Habitual physical activity, aerobic capacity and metabolic control in patients with newly-diagnosed Type 2 (non-insulin-dependent) diabetes mellitus: effect of 1-year diet and exercise intervention
}

\author{
E. Vanninen ${ }^{1}$, M. Uusitupa ${ }^{2}$, O. Siitonen ${ }^{3}$, J. Laitinen $^{2}$ and E. Länsimies ${ }^{1}$ \\ Departments of ${ }^{1}$ Clinical Physiology, ${ }^{2}$ Clinical Nutrition and ${ }^{3}$ Medicine, Kuopio University Hospital, Kuopio, Finland
}

\begin{abstract}
Summary. The aim of this study was to assess the effects of a 1-year intensified diet and exercise education regimen on habitual physical activity and aerobic capacity in middle-aged, obese patients with newly-diagnosed Type 2 (non-insulin-dependent) diabetes mellitus. In addition, we analysed whether the level and the changes in physical activity and aerobic capacity are related to the metabolic control of diabetes. After a 3 -month basic education programme, 78 patients ( 45 men, 33 women) were randomly placed in an intervention or conventionally treated group. The intervention group received intensified diet education and continuous encouragement to increase physical activity which was monitored using exercise records and questionnaires. Aerobic capacity was assessed by measuring oxygen uptake at anaerobic threshold and at peak exercise. The proportion of patients with regular recreational exercise increased from $24 \%$ to $38 \%$ in the intervention men $(0.10<p<0.20)$, remained at $54 \%$ in the conventionally treated men, increased from $53 \%$ to $70 \%$ in the intervention women $(0.10<p<0.20)$ and from $31 \%$ to $50 \%$ $(0.10<p<0.20)$ in the conventionally treated women. No measurable improvement was found in oxygen uptake in any of the groups. When the groups were combined, $\mathrm{HbA}_{1 \mathrm{c}}$
\end{abstract}

showed an inverse correlation with oxygen uptake at anaerobic threshold $(r=-0.27, p<0.01)$ and maximum oxygen uptake $(r=-0.28, p<0.01)$ at 12 months. The change in maximum oxygen uptake was linearly correlated with the change in HDL-cholesterol $(r=0.28, p<0.01)$ and those patients with improved aerobic capacity $(n=37)$ had higher HDL-cholesterol level at the end of the study than those $(n=41)$ with unaltered or decreased aerobic capacity $\left(1.27 \pm 0.27\right.$ vs $1.12 \pm 0.25 \mathrm{mmol} \cdot 1^{-1}$, mean $\left.\pm \mathrm{SD} ; p<0.05\right)$. In conclusion, in this long-term prospective study repeated encouragement and follow-up using exercise records was not sufficient to induce a significant increase in physical activity and an improvement in aerobic capacity in diabetic patients. Our results suggest, however, that high aerobic capacity is beneficial for glycaemic control, and on the other hand, even slight increase in aerobic capacity is associated with an increase in HDL-cholesterol level.

Key words: Type 2 (non-insulin-dependent) diabetes mellitus, blood glucose, exercise therapy, physical fitness, oxygen consumption, anaerobic threshold.
Physical training is recommended as an adjunct therapy to diet in the management of Type 2 (non-insulin-dependent) diabetes mellitus $[1,2]$. Recent reviews have pointed out the potential for exercise to improve insulin sensitivity, glucose tolerance and long-term glycaemic control measured by $\mathrm{HbA}_{1 \mathrm{c}}$ in diabetic patients [3-9]. Furthermore, there are suggestive data showing that regular physical activity may induce favourable changes in serum lipid profile [10-12]. The benefits in clinical trials, however, have been quite modest from the clinical viewpoint.

Specific and detailed recommendations are available for prescribing exercise for diabetic patients, which suggest regular exercise (50-70\% of an individual's maximal oxygen uptake) at least three times a week with each ses- sion lasting $20-45 \mathrm{~min}$ [13]. The goal of the training is to improve aerobic performance. However, it has been argued that the feasibility of exercise at this level is poor in the diabetic patients [14]. In patients with Type 2 diabetes the main problems are old age, overweight, orthopaedic problems and co-existing cardiovascular diseases which may hinder even moderate physical activity. So far, there are no larger studies available on habitual physical activity and the impact of diabetic education on it in patients with Type 2 diabetes. In addition, the possible synergistic effect of exercise and appropriate diet therapy in the long-term treatment of Type 2 diabetes in the clinical setting needs further evaluation.

This report is based on a randomised controlled trial which was carried out to assess whether intensified treat- 
ment including diet and exercise intervention would be more beneficial than conventional treatment in newlydiagnosed diabetic patients. This study setting gave us an opportunity to prospectively assess habitual physical activity and its relationship to aerobic capacity and metabolic control in these patients. Our study also provided information on whether Type 2 diabetic patients are compliant and willing to exercise according to the recommendations on a long-term basis. The detailed results on metabolic control and cardiovascular risk factors in respect to effectiveness of diet therapy will be reported elsewhere.

\section{Subjects and methods}

\section{Subjects}

During the period 1987-1989, the physicians working in five rural and one urban health centres covering a total population of 130,000 inhabitants were asked to refer all 40 - to 64-year old subjects with fasting venous blood glucose greater than $6.7 \mathrm{mmol} / \mathrm{l}$ in repeated measurements for further evaluation. Altogether 108 subjects were originally reserved for the study, but seven of them did not fulfil the diagnostic criteria for Type 2 diabetes [15], four had a chronic disease affecting glucose tolerance, seven were not willing to participate in the study and four left the study during the intervention phase. In addition, seven patients did not perform the exercise tests at 0 and 12 months due to various reasons and in one patient the respiratory gas exchange measurements were unreliable, and these patients were excluded from the present analyses as well.

The mean fasting blood glucose at the primary diagnosis of diabetes was $11.5 \pm 4.2 \mathrm{mmol} \cdot 1^{-1}$ (mean $\pm \mathrm{SD}$ ). During the two months delay from diagnosis to the baseline examination, the decrease in fasting blood glucose and body weight were $3.3 \pm$ $4.0 \mathrm{mmol} \cdot 1^{-1}$ and $1.8 \pm 3.9 \mathrm{~kg}$, respectively. The age and anthropometric data of the patients at baseline are shown in Table 1 . Fortytwo percent of the men and $58 \%$ of the women had hypertension. Ischaemic heart disease was present in $42 \%$ of the men and in $30 \%$ of the women, although only $18 \%$ of the men and $16 \%$ of the women reported having symptoms of angina pectoris [16]. One man was on glibenclamide therapy at baseline and four men and three women were at the end of the study. Forty-five percent of the patients were non-smokers, $37 \%$ were ex-smokers and $18 \%$ were current smokers. The study was approved by the Ethics Committee of Kuopio University Hospital. All patients gave oral informed consent before participating in the study.

\section{Study design}

After a 3-month basic education programme patients were randomly placed in one of two groups for the comparison of intensified treatment (the intervention group) and standard treatment (the conventional treatment group). The intervention group was treated at the outpatient clinic of the Department of Medicine, Kuopio University Hospital. The conventional treatment group was treated at the community health centres that originally referred the patients to the study.

During the 12-month intervention phase the intervention group visited the outpatient clinic six times at 2 -month intervals. At every visit they were seen by a physician, a dietitian and a nurse specialised in diabetes education. The physician was responsible for the general motivation and follow-up of the patient. The dietitian was responsible for the intensified diet education. The nurse was responsible for further patient education including the follow-up of metabolic control. The conventional treatment group was advised to visit the local community health centres regularly at $2-3$ month intervals. This group visited the outpatient clinic at 6 and 12 months after the original grouping.

\section{Schedule of measurements}

At baseline ( 3 months prior to the study), the following examinations were done: medical history including data on medication, smoking, alcohol consumption and habitual physical activity [17], anthropometric measurements, cardiopulmonary exercise test, fasting blood glucose, $\mathrm{HbA}_{1 \mathrm{c}}$, fasting plasma insulin and serum lipids; at the time of the group selection ( 0 months): presence of cardiovascular symptoms, body weight, cardiopulmonary exercise test, fasting blood glucose, $\mathrm{HbA}_{\mathrm{Ic}}$ and serum lipids; and at the end of the study (12 months): medical history, cardiovascular symptoms, anthropometric measurements, cardiopulmonary exercise test, fasting blood glucose, $\mathrm{HbA}_{\mathrm{lc}}$, fasting plasma insulin and serum lipids.

\section{Diet and exercise intervention}

During the basic education programme all patients visited the outpatient clinic twice (at baseline and after 6 weeks) and received basic information concerning the potential benefits of physical activity. The dietary instructions included a reduction in the intake of total energy, total fat and dietary cholesterol.

After the group selection the physician gave printed and oral instructions for effective exercise training to every patient in the intervention group. Thereafter, physical activity was regularly monitored by daily exercise records. At each visit throughout the whole $12-$ month intervention phase the patients in the intervention group were encouraged to increase physical activity. No written individual instructions were used and no supervised exercise sessions were organised. The types of exercise proposed were walking, jogging, cycling, swimming or cross-country skiing. The goal was to increase the frequency of exercise sessions to 3-4 times a week, each lasting $30-60 \mathrm{~min}$. The recommended mean heart rate during exercise sessions was $110-140$ beats per min.

The goals of intensified diet education were weight reduction, normoglycaemia and correction of dyslipidaemias. The means of the diet therapy were individually planned energy restriction, restriction of the intake of total fat, and especially saturated fatty acids and dietary cholesterol, a moderate increment of unsaturated fatty acids and foods containing complex carbohydrates, especially soluble fibre. In addition, the target food habits were regular eating patterns and to moderate the amount of food consumed.

\section{Classification of physical activity}

For secondary analyses concerning the level and changes in physical activity during the intervention phase, the intervention and conventionally treated groups were combined, and thereafter, both men and women were divided into three groups by the level of physical activity at 12 months: (1) sedentary group (patients without regular occupational or recreational physical activities), (2) moderately exercising group (patients with moderate occupational and/or recreational physical activities) and (3) intensively exercising group (patients with heavy work and/or regular exercise training at least three times a week, each session lasting a minimum of $30 \mathrm{~min}$ ).

\section{Anthropometric measurements}

Body weight was measured to the nearest $1.0 \mathrm{~kg}$ with an electric weighing machine (Seca, Modell 708, Hamburg, FRG). Fat free body mass (FFM) was calculated according to the method of Durn- 
Table 1. Age and anthropometric data of the patients at baseline

\begin{tabular}{lcc}
\hline & Men & Women \\
& $n=45$ & $n=33$ \\
\hline Age (years) & $53 \pm 7$ & $54 \pm 6$ \\
Height $(\mathrm{m})$ & $1.74 \pm 0.05$ & $1.58 \pm 0.07$ \\
Body weight $(\mathrm{kg})$ & $95 \pm 12$ & $88 \pm 16$ \\
Body mass index $\left(\mathrm{kg} \cdot \mathrm{m}^{-2}\right)$ & $32 \pm 4$ & $35 \pm 6$ \\
Percentage of body fat $(\%)$ & $32 \pm 5$ & $45 \pm 4$ \\
\hline
\end{tabular}

ing and Womersley [18] by using an average of three measurements obtained from triceps, subscapular and suprailiac skinfolds. Body mass index was calculated as weight/height squared $\left(\mathrm{kg} \cdot \mathrm{m}^{-2}\right)$.

\section{Cardiopulmonary exercise test}

Cardiopulmonary exercise test was done as previously described [19]. Briefly, the exercise test was performed with a bicycle ergometer in an upright position until exhaustion [20]. During the test a 12-lead ECG, blood pressure, heart rate, subjective symptoms and perceived exertion were recorded. Respiratory gas exchange was analysed continuously during the exercise test with a computerbased system (2001 Cad/Net Cardiopulmonary Exercise System, Medical Graphics Corp., Saint Paul, Minn., USA). Moving eightbreath averages from representative points were used for the data analysis. Peak values of oxygen uptake were used for maximum attainable oxygen uptake ( $\dot{\mathrm{V}} \mathrm{O}_{2}$ max). Anaerobic threshold ( $\left.\dot{\mathrm{V}} \mathrm{O}_{2} a t\right)$ was determined from the respiratory gas exchange data by using standard criteria [21]. The exercise test was omitted in the first 9 men and 12 women at -3 months baseline examination.

\section{Biochemical determinations}

All blood samples were taken between 07.30 hours and 09.00 hours after a 12 -h overnight fast prior to the exercise test. The glucose oxidase method was used to measure blood glucose (Glucose Auto \& Stat HGA-1120 analyzer, Daiichi Co, Kyoto, Japan). Commercial fast protein liquid chromatography (Pharmacia Fine Chemicals AB, Uppsala, Sweden) was used to measure $\mathrm{HbA}_{1 c}$. Plasma insulin was analysed with the Phadeseph Insulin RIA 100 method (Pharmacia Diagnostica AB Uppsala, Sweden). Enzymatic methods were used for the determination of serum cholesterol and triglycerides (Monotest and Test-Combination, respectively, Boehringer Mannheim, Mannheim, FRG). HDL-cholesterol was determined after precipation with dextran sulphate and $\mathrm{MgCl}_{2}$ [22].

\section{Statistical analysis}

Repeated measures analysis of variance was used for orienting analyses. Thereafter, analysis of variance and Student's $t$-test were used to analyse differences between the groups in continuous variables. The chi-square test was used to analyse frequency distribution. The significance of the changes in each group were analysed by paired $t$-test in continuous variables, by McNemar's test in dichotomous variables and by a test of proportions based on standardised normal distribution in variables expressed as proportions [23]. Linear correlation coefficients and multiple regression procedures were used to analyse associations between continuous variables. Plasma insulin values were analysed after a logarithmic transformation. Differences were considered to be statistically significant if the $p$-value was less than 0.05 . All results are expressed as mean \pm SD. All data were analysed with an IBM PC /AT compatible computer using the SPSS/PS +3.1 statistical package (SPSS Inc., Chicago, Ill., USA).

\section{Results}

\section{Changes in habitual physical activity}

Both occupational and recreational physical activities in each group are summarised in Table 2 . At the end of the study $22 \%$ of the men (conventional treatment group $29 \%$, intervention group $14 \%$, NS) and $30 \%$ of the women (conventional treatment group $19 \%$, intervention group $41 \%$, NS) reported that they had markedly increased recreational physical activity during the study. There were no differences in occupational and recreational physical activity between the groups at the -3 and 12 month examinations.

\section{Changes in body size and metabolic control}

Significant decreases were observed during the basic education programme in body weight, fasting blood glucose and $\mathrm{HbA}_{1 \mathrm{c}}$ but not in serum lipids in either the intervention or conventionally treated groups (Table 3 ).

During the intervention phase the intervention men continued to lose weight while the conventionally treated men gained weight (Table 3 ). The intervention women was the only group to show continued improvement in fasting blood glucose and $\mathrm{HbA}_{1 \mathrm{c}}$. Fasting plasma insulin levels decreased and serum HDL-cholesterol levels increased significantly in the intervention men and women during the intervention phase. A significant decrease in serum triglycerides was observed in the intervention men. At 12 months the intervention women had lower $\mathrm{HbA}_{1 \mathrm{c}}$ and serum cholesterol levels than the conventionally treated women.

\section{Changes in aerobic capacity}

There were no significant changes or differences in $\dot{\mathrm{V}} \mathrm{O}_{2}$ at or $\dot{\mathrm{V}} \mathrm{O}_{2}$ max between the intervention and conventional treatment groups in either sex at any of the three exercise tests irrespective of whether aerobic capacity was expressed in absolute values $\left(1 \cdot \mathrm{min}^{-1}\right)$ or

Table 2. Distribution of occupational and recreational physical activity in the conventional treatment and intervention groups at baseline and at the end of the study ( $-3 / 12$ months)

\begin{tabular}{|c|c|c|c|c|}
\hline & \multicolumn{2}{|l|}{ Men } & \multicolumn{2}{|l|}{ Women } \\
\hline & $\begin{array}{l}\text { Conven- } \\
\text { tional } \\
n=24\end{array}$ & $\begin{array}{l}\text { Inter- } \\
\text { vention } \\
n=21\end{array}$ & $\begin{array}{l}\text { Conven- } \\
\text { tional } \\
n=16\end{array}$ & $\begin{array}{l}\text { Inter- } \\
\text { vention } \\
n=17\end{array}$ \\
\hline \multicolumn{5}{|c|}{ Occupational physical activity (\%) } \\
\hline $\begin{array}{l}\text { No regular work } \\
\text { Light work } \\
\text { Moderate work } \\
\text { Heavy work }\end{array}$ & $\begin{array}{c}46 / 50 \\
33 / 33 \\
13 / 13 \\
8 / 4\end{array}$ & $\begin{array}{l}38 / 43 \\
14 / 24 \\
19 / 19 \\
29 / 14\end{array}$ & $\begin{array}{l}38 / 44 \\
19 / 19 \\
31 / 25 \\
12 / 12\end{array}$ & $\begin{array}{l}47 / 47 \\
18 / 12 \\
23 / 29 \\
12 / 12\end{array}$ \\
\hline \multicolumn{5}{|c|}{ Recreational physical activity (\%) } \\
\hline $\begin{array}{l}\text { Sedentary } \\
\text { Occasional exercise } \\
\text { Regular exercise }\end{array}$ & $\begin{array}{l}25 / 13 \\
21 / 33 \\
54 / 54\end{array}$ & $\begin{array}{l}43 / 29 \\
33 / 33 \\
24 / 38\end{array}$ & $\begin{array}{r}63 / 37 \\
6 / 13 \\
31 / 50\end{array}$ & $\begin{array}{l}35 / 12 \\
12 / 18 \\
53 / 70\end{array}$ \\
\hline
\end{tabular}

${ }^{a}$ originally a 7 level scale 
Table 3. Body mass index, metabolic control and aerobic capacity at baseline ( -3 months), at the time of group selection ( 0 months) and at the end of the study ( 12 months) in conventional treatment and intervention groups by sex

\begin{tabular}{|c|c|c|c|c|}
\hline \multirow[b]{2}{*}{$\operatorname{Sex}$} & \multirow[b]{2}{*}{ Group } & \multicolumn{3}{|l|}{ Time } \\
\hline & & -3 months & 0 months & 12 months \\
\hline \multicolumn{5}{|c|}{$B M I\left(\mathrm{~kg} \cdot \mathrm{m}^{-2}\right)$} \\
\hline \multirow[t]{2}{*}{ Men } & Conventional & $31.2 \pm 3.5$ & $30.1 \pm 3.1^{c}$ & $30.9 \pm 3.3^{c}$ \\
\hline & Intervention & $31.9 \pm 3.7$ & $31.1 \pm 3.7^{\circ}$ & $30.5 \pm 3.6^{b}$ \\
\hline \multirow[t]{2}{*}{ Women } & Conventional & $35.5 \pm 5.9$ & $34.2 \pm 6.2^{d}$ & $34.0 \pm 5.9$ \\
\hline & Intervention & $35.1 \pm 3.7$ & $33.4 \pm 6.7^{d}$ & $32.6 \pm 6.5$ \\
\hline \multicolumn{5}{|c|}{ Fasting blood glucose $\left(\mathrm{mmol} \cdot \mathrm{l}^{-1}\right)$} \\
\hline \multirow[t]{2}{*}{ Men } & Conventional & $8.1 \pm 2.8$ & $6.7 \pm 2.2^{d}$ & $7.3 \pm 2.2$ \\
\hline & Intervention & $8.1 \pm 2.7$ & $6.6 \pm 2.1^{c}$ & $6.7 \pm 2.1$ \\
\hline \multirow[t]{2}{*}{ Women } & Conventional & $10.1 \pm 4.1$ & $8.5 \pm 3.5^{\mathrm{b}}$ & $7.2 \pm 1.9$ \\
\hline & Intervention & $6.9 \pm 1.6$ & $6.3 \pm 1.2^{\mathrm{b}}$ & $5.7 \pm 1.4^{\mathrm{a}}$ \\
\hline \multicolumn{5}{|c|}{$H b A_{1 \mathrm{c}}(\%)$} \\
\hline \multirow[t]{2}{*}{ Men } & Conventional & $8.7 \pm 2.3$ & $7.3 \pm 1.7^{\mathrm{c}}$ & $7.4 \pm 1.6$ \\
\hline & Intervention & $8.5 \pm 2.0$ & $7.1 \pm 1.5^{\mathrm{d}}$ & $7.0 \pm 1.9$ \\
\hline \multirow[t]{2}{*}{ Women } & Conventional & $9.4 \pm 3.1$ & $8.1 \pm 2.4^{b}$ & $7.2 \pm 1.6$ \\
\hline & Intervention & $8.6 \pm 2.4$ & $7.1 \pm 1.5$ & $6.2 \pm 1.0^{\mathrm{a}, \mathrm{b}}$ \\
\hline \multicolumn{5}{|c|}{ Fasting plasma insulin $\left(\mathrm{pmol} \cdot 1^{-1}\right)$} \\
\hline \multirow[t]{2}{*}{ Men } & Conventional & $187 \pm 175$ & - & $139 \pm 99$ \\
\hline & Intervention & $167 \pm 76$ & - & $130 \pm 96^{b}$ \\
\hline \multirow[t]{2}{*}{ Women } & Conventional & $175 \pm 94$ & - & $154 \pm 80$ \\
\hline & Intervention & $169 \pm 69$ & - & $130 \pm 51^{c}$ \\
\hline \multicolumn{5}{|c|}{ Serum cholesterol $\left(\mathrm{mmol} \cdot 1^{-1}\right)$} \\
\hline \multirow[t]{2}{*}{ Men } & Conventional & $6.4 \pm 1.1$ & $6.1 \pm 1.0$ & $6.2 \pm 1.0$ \\
\hline & Intervention & $6.5 \pm 1.6$ & $6.3 \pm 1.2$ & $6.0 \pm 1.0$ \\
\hline \multirow[t]{2}{*}{ Women } & Conventional & $6.5 \pm 0.9$ & $6.5 \pm 0.8$ & $6.7 \pm 0.7$ \\
\hline & Intervention & $6.1 \pm 1.1$ & $6.0 \pm 1.2$ & $6.0 \pm 1.0^{\mathrm{a}}$ \\
\hline \multicolumn{5}{|c|}{ Serum HDL-Cholesterol $\left(\mathrm{mmol} \cdot \mathrm{I}^{-1}\right)$} \\
\hline \multirow[t]{2}{*}{ Men } & Conventional & $1.10 \pm 0.24$ & $1.10 \pm 0.24$ & $1.15 \pm 0.27$ \\
\hline & Intervention & $1.03 \pm 0.34$ & $1.00 \pm 0.28$ & $1.11 \pm 0.28^{b}$ \\
\hline \multirow[t]{2}{*}{ Women } & Conventional & $1.19 \pm 0.29$ & $1.25 \pm 0.36$ & $1.29 \pm 0.29$ \\
\hline & Intervention & $1.09 \pm 0.29$ & $1.13 \pm 0.18$ & $1.25 \pm 0.22^{c}$ \\
\hline \multicolumn{5}{|c|}{ Serum triglycerides $\left(\mathrm{mmol} \cdot 1^{-1}\right)$} \\
\hline \multirow[t]{2}{*}{ Men } & Conventional & $2.9 \pm 1.9$ & $2.3 \pm 1.4$ & $2.3 \pm 1.0$ \\
\hline & Intervention & $3.0 \pm 1.6$ & $2.9 \pm 1.7$ & $2.0 \pm 0.9^{c}$ \\
\hline Women & Conventional & $2.8 \pm 1.6$ & $2.3 \pm 1.5$ & $2.5 \pm 1.6$ \\
\hline & Intervention & $2.7 \pm 1.6$ & $2.1 \pm 1.0$ & $2.0 \pm 0.9$ \\
\hline Oxyger & ptake at anaerob & hreshold (m & $\left.\cdot \min ^{-1} \cdot \mathrm{kg}^{-1}\right)$ & \\
\hline Men & Conventional & $13.7 \pm 2.4$ & $14.4 \pm 2.9$ & $15.0 \pm 3.2$ \\
\hline & Intervention & $14.7 \pm 4.3$ & $14.5 \pm 3.4$ & $15.1 \pm 4.1$ \\
\hline Women & Conventional & $12.2 \pm 2.0$ & $12.8 \pm 3.3$ & $12.6 \pm 2.8$ \\
\hline & Intervention & $12.0 \pm 1.9$ & $12.7 \pm 2.5$ & $12.8 \pm 2.4$ \\
\hline Maxim & noxygen uptake & $\left.1 \cdot \min ^{-1} \cdot \mathrm{kg}^{-1}\right)$ & & \\
\hline Men & Conventional & $23.9 \pm 5.3$ & $24.7 \pm 5.7^{b}$ & $23.9 \pm 5.4$ \\
\hline & Intervention & $22.0 \pm 6.6$ & $24.1 \pm 5.8$ & $24.8 \pm 6.9$ \\
\hline Women & Conventional & $15.7 \pm 3.8$ & $18.7 \pm 5.4$ & $18.2 \pm 4.7$ \\
\hline & Intervention & $18.3 \pm 2.7$ & $18.9 \pm 3.9$ & $19.4 \pm 3.6$ \\
\hline
\end{tabular}

Values mean $\pm \mathrm{SD}$. ${ }^{a} p<0.05$ conventional treatment vs intervention group at 12 months; ${ }^{\mathrm{b}} p<0.05 ;{ }^{\mathrm{c}} p<0.01 ;{ }^{\mathrm{c}} p \leq 0.001$ change to previous examination

relative to total body weight $\left(1 \cdot \mathrm{min}^{-1} \cdot \mathrm{kg}^{-1}\right.$, Table 3$)$ or FFM $\left(1 \cdot \mathrm{min}^{-1} \cdot \mathrm{kg}^{-1}\right)$. When those men with myocardial infarction $(n=2)$ or stroke $(n=1)$ during the study were excluded, the conventionally treated men showed a significant increase in $\dot{\mathrm{V}} \mathrm{O}_{2}$ at (from $1.29 \pm 0.35$ to $1.44 \pm 0.35 \mathrm{I} \cdot \mathrm{min}^{-1}, p<0.05$ ), but still no change in $\dot{\mathrm{V}} \mathrm{O}_{2} \max$ was observed. In the conventionally treated men $\dot{\mathrm{V}} \mathrm{O}_{2}$ at was reached at higher percentage of
$\dot{\mathrm{V}} \mathrm{O}_{2}$ max at end of the study than at the group selection $(59 \pm 9$ vs $63 \pm 8 \%, p<0.05)$.

\section{Changes in body composition, metabolic control, and respiratory gas exchange in relation to habitual physical activity}

For the secondary analyses both men and women were divided into sedentary, moderately active and intensively exercising groups (see Classification of physical activity). There were no differences between these groups in age, use of cardiovascular drugs or distribution in the intervention or conventional treatment groups. In men, the intensively exercising group improved $\dot{\mathrm{V}} \mathrm{O}_{2}$ at from 1.31 \pm 0.23 to $1.53 \pm 0.331 \cdot \mathrm{min}^{-1}(p<0.01)$ during the intervention phase, but no improvement was observed in $\dot{\mathrm{V}} \mathrm{O}_{2}$ max. None of the groups showed significant improvement of metabolic control and no differences were observed in metabolic control between the three groups at 12 months (Table 4). In women, none of the groups showed any improvement in aerobic capacity during the intervention phase. The moderately exercising group of women showed a significant decline in fasting blood glucose levels from $7.6 \pm 3.0$ to $6.5 \pm 0.9 \mathrm{mmol} \cdot \mathrm{l}^{-1}(p<0.05)$ during the intervention phase, but no significant differences were observed between the groups at 12 months (Table 4).

\section{Correlations between aerobic function and metabolic control}

In men, $\dot{\mathrm{V}} \mathrm{O}_{2}$ at $(r=0.30, p<0.05)$ and $\dot{\mathrm{V}} O_{2} \max (r=0.36$, $p<0.01$ ) were inversely correlated with $\mathrm{HbA}_{1 c}$ at 12 months, but not a 0 months. In women, the correlation between aerobic capacity and glycaemic control was lower, and this association was not found in the intervention women, whose blood glucose levels were almost normalised at this stage. $\dot{\mathrm{V}} \mathrm{O}_{2}$ at /FFM and $\dot{\mathrm{V}} \mathrm{O}_{2}$ max/FFM in relation to $\mathrm{HbA}_{1 \mathrm{c}}$ at 12 months are shown in Figure 1. The change in aerobic capacity and the change in $\mathrm{HbA}_{1 c}$ were not correlated in either sex.

No correlation was observed between aerobic power and serum lipids at any of the examinations. However, those patients who showed an increase in $\dot{\mathrm{V}} \mathrm{O}_{2}$ max during the intervention phase ( $n=37$, men and women combined) had higher HDL-cholesterol levels at 12 months than those $(n=41)$ who bad decreased $\mathrm{V}_{2} \max$ $\left(1.27 \pm 0.27\right.$ vs $\left.1.12 \pm 0.25 \mathrm{mmol} \cdot 1^{-1}, p<0.05\right)$. This difference could not be explained by smoking habits. The improvement in $\dot{\mathrm{V}} \mathrm{O}_{2}$ max was linearly correlated with the increase in HDL-cholesterol (Fig. 2). This correlation was significant in men $(r=0.33, p<0.05)$, but not in women $(r=0.13)$. In a multiple regression model including the changes in $\mathrm{VO}_{2} \max$, body weight, fasting blood glucose and serum insulin as independent variables and sexes combined, the only significant variables explaining the variance of the change in HDL-cholesterol were fasting blood glucose and $\dot{\mathrm{V}} \mathrm{O}_{2} \max \left(r^{2}=0.17, \quad \mathrm{~F}=7.56\right.$, $p \leq 0.001$ ). 
Table 4. Body mass index, metabolic control and aerobic capacity in relation to habitual physical activity at the end of the study (12 months) in the conventional treatment and intervention groups combined by sex

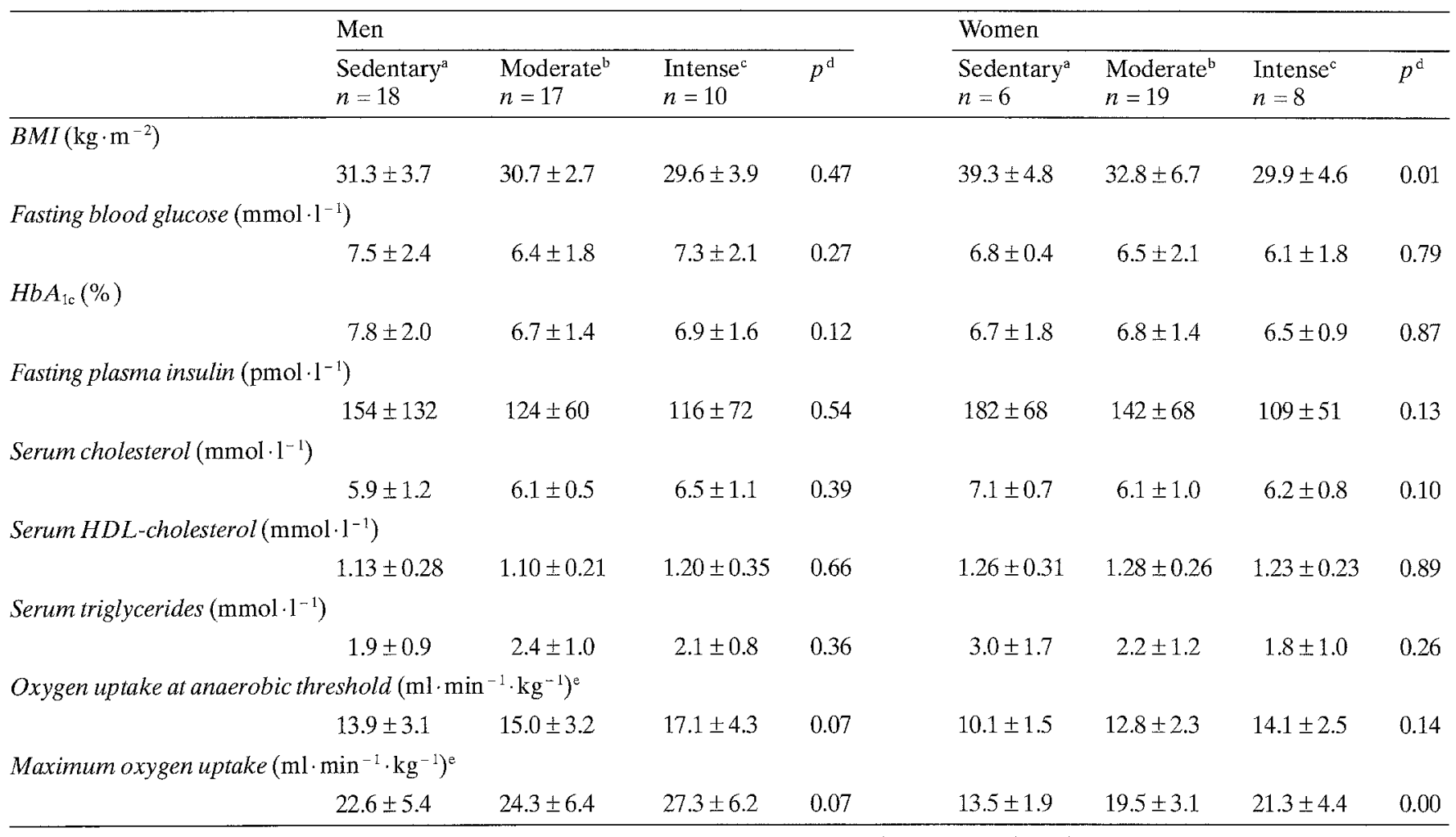

All values mean \pm SD. a Sedentary, subjects without regular occupational or recreational physical activities; ${ }^{b}$ moderate, subjects with moderate occupational or recreational physical activities; ${ }^{\mathrm{c}}$ intense, subjects with heavy work and/or regular exercise training at least three times a week, each session minimum $30 \mathrm{~min} ;{ }^{\mathrm{d}}$ analysis of variance; ${ }^{\mathrm{e}}$ oxygen uptake/total body weight
In women, both $\dot{\mathrm{V}} \mathrm{O}_{2}$ at/FFM $(r=-0.34, p<0.05)$ and $\dot{\mathrm{V}} \mathrm{O}_{2}$ max/FFM $(r=-0.36, p<0.05)$ were inversely correlated with body weight at the end of the study suggesting an adverse effect of obesity on aerobic capacity. In men, such a relationship could not be demonstrated at any of the examinations.

\section{Discussion}

The main findings of the present study were: (1) repeated encouragement to increase physical activity and follow-up by exercise records was not sufficient to induce an improvement in $\mathrm{V}_{2}$ max in newly-diagnosed diabetic patients during a 12-month period; (2) a significant inverse correlation between $\mathrm{HbA}_{1 \mathrm{c}}$ and aerobic capacity; and (3) an association between the changes of aerobic capacity and HDL-cholesterol independent of the change in body weight or metabolic control.

The strategy we chose to increase physical activity in the intervention group (i.e. close follow-up with daily exercise records without organised and supervised exercise sessions) is the way that was believed to be the most suitable and cost-effective for the clinical practice. It can be speculated that in the intervention group exercise received less relative attention than diet, and that the reverse could be true of the conventionally treated group for which no dietitians participated in the treatment. This could explain in part why no differences were found in recreational physical activity between the conventionally treated and intervention groups at the end of the study.

Numerous clinical studies in diabetic subjects have demonstrated that supervised, intensive training improves aerobic capacity. The problem, however, is the feasibility of such training in the long-term [14]. A recent large prospective study reported that only $20-30 \%$ of the diabetic patients continued taking part in organised exercise training after 2 years [24]. These findings, and also our results show that the main problem in exercise training in diabetic patients is motivation and compliance with instructions. In diabetic subjects, the main hindrances for effective exercise training are linked to obesity and cardiovascular morbidity. It is likely that those instructions for exercise training which have been made for healthy subjects are not well-suited or sufficient for diabetic patients. Individualised instructions could be more effective to increase physical exercise in these patients. In the clinical practice, this could mean more widespread use of exercise physiologists.

Although $\dot{\mathrm{V}} \mathrm{O}_{2}$ max did not show any improvement in the present study, some improvement was observed in $\dot{\mathrm{V}} \mathrm{O}_{2}$ at. It is possible that $\dot{\mathrm{V}} \mathrm{O}_{2}$ at is more sensitive in detecting small changes in aerobic performance than $\dot{\mathrm{V}} \mathrm{O}_{2}$ max in diabetic patients. In previous studies concerning the potential benefits of exercise in Type 2 diabetes the only clear criterion for effective training was improved $\mathrm{V}_{2}$ max, but 

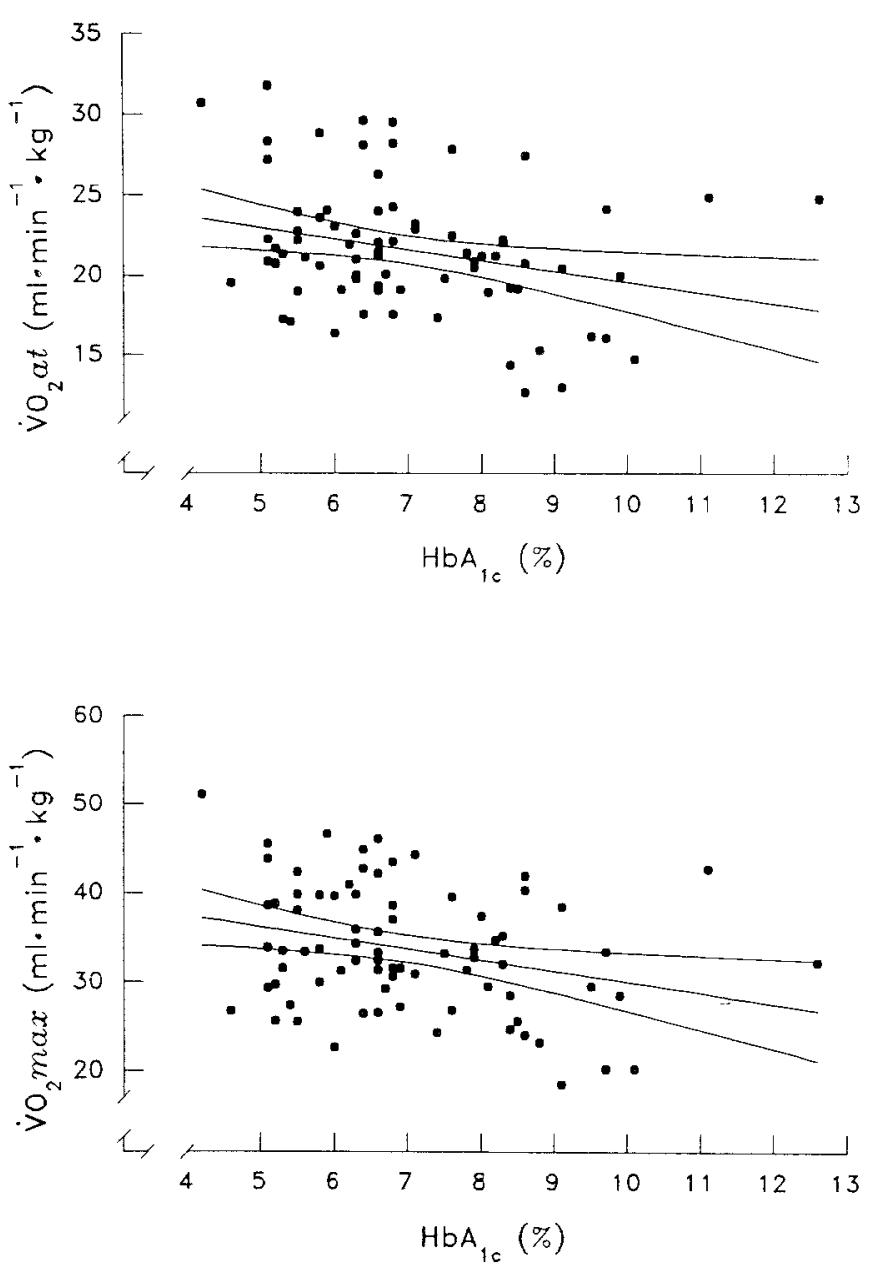

Fig. 1. $\mathrm{HbA}_{\mathrm{Ic}}$ in relation to $\dot{\mathrm{V}} \mathrm{O}_{2}$ at/FFM $(r=0.27, p<0.01)$ and $\dot{\mathrm{V}} \mathrm{O}_{2} \max / \mathrm{FFM}(r=0.28, p<0.01)$ at 12 months in the study population $(n=78)$. Correlation lines with $95 \%$ confidence intervals are shown

none of these studies have evaluated changes in $\dot{\mathrm{V}} \mathrm{O}_{2}$ at. $\dot{\mathrm{V}} \mathrm{O}_{2}$ at could also be useful in planning individual exercise programmes for diabetic patients [25].

In the present study, a significant inverse correlation between aerobic function and $\mathrm{Hb}_{\mathrm{bc}}$ was observed, but the decrease in $\mathrm{HbA}_{\mathrm{lc}}$ was not related to the change in aerobic capacity. In contrast, the change in aerobic capacity showed a linear correlation with the increase in HDLcholesterol independent of metabolic control. These findings suggest that both the level of aerobic capacity and the changes in it should be evaluated when assessing possible benefits of exercise in Type 2 diabetes.

Some studies have demonstrated that exercise training decreases $\mathrm{HbA}_{1 \mathrm{c}}$ levels [26-28], but no inverse linear correlation has been previously reported between $\mathrm{HbA}_{1 \mathrm{c}}$ and aerobic capacity. The blood glucose lowering effect of exercise is largely due to the cumulative effects of single exercise bouts $[4,6,7,9]$. The interaction between glycaemic control and aerobic capacity may, however, be more complex because it has been suggested that lowered $\dot{\mathrm{V}} \mathrm{O}_{2}$ at in diabetic subjects is due to a high $\mathrm{HbA}_{1 \mathrm{c}}$ level through increased oxygen affinity [25]. It is also possible that improved glycaemic control per se may improve aerobic function as shown previously by our group [19]. In the present study, the intervention women with almost normal blood glucose levels showed no correlation between $\mathrm{HbA}_{1 \mathrm{c}}$ and aerobic capacity at 12 months. Thus, the inverse correlation between $\mathrm{HbA}_{1 \mathrm{c}}$ may be limited to moderate hyperglycaemia.

The improvement in HDL-cholesterol was related both to the changes in blood glucose level and aerobic capacity in the present study, but not to the reduction in body weight. Elsewhere, it has been shown that weight reduction achieved by very-low-calorie diet induces an elevation in HDL-cholesterol in Type 2 diabetes [29]. Few studies have previously suggested that exercise improves serum lipid profile in Type 2 diabetes [10-12]. However, it has been speculated that the most important impact of exercise in Type 2 diabetes is the beneficial effect on cardiovascular risk factors $[6,8]$. Recently, a study on obese healthy subjects showed that combined diet and exercise training resulted in a significantly higher increase in HDLcholesterol than diet alone [30].

In conclusion, there was no improvement in $\dot{\mathrm{V}} \mathrm{O}_{2}$ max among newly-diagnosed patients with Type 2 diabetes after a 12-month diet and exercise programme. However, the inverse relationship observed between aerobic capacity and $\mathrm{HbA}_{1 \mathrm{c}}$, and the linear correlation between an improved aerobic capacity and increased HDL-cholesterol, suggest that regular physical activity resulting in an improved aerobic capacity is beneficial for these patients.

Acknowledgements. This study has been supported financially by grants from the Juho Vainio Foundation, the Yrjö Jahnsson Foundation and in part by the Academy of Finland.

\section{References}

1. National Institutes of Health (1987) Consensus development conference on diet and exercise in non-insulin-dependent diabetes mellitus. Diab Care 10: 639-644

2. Alberti KGMM, Gries FA (1988) Management of non-insulindependent diabetes mellitus in Europe: A consensus view. Diab Med 5:275-281

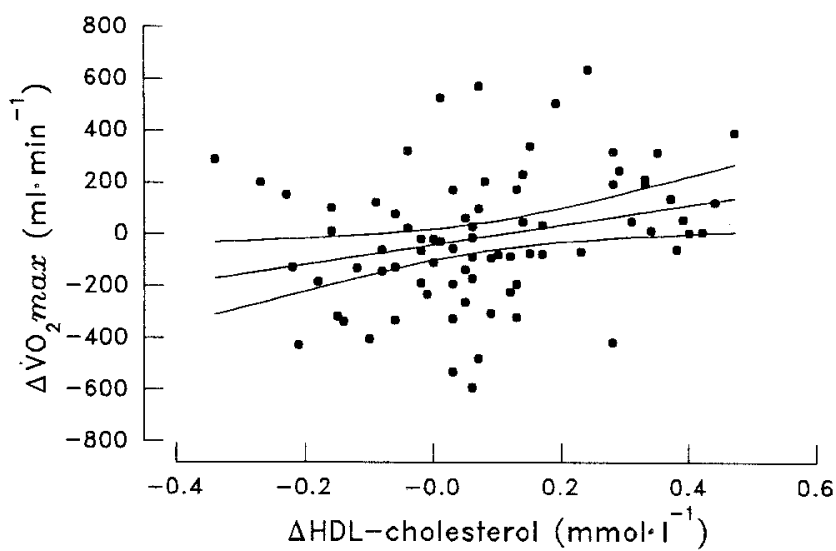

Fig. 2. The change in $\dot{V} \mathrm{O}_{2}$ max during in tervention phase in relation to the change in HDL-cholesterol $(r=0.28, p<0.01)$ in the study population $(n=78)$. Correlation line with $95 \%$ confidence intervals is shown 
3. Björntorp P, Krotkiewski M (1985) Exercise in diabetes mellitus. Acta Med Scand 217:3-7

4. Koivisto V, Yki-Järvinen H, DeFronzo RA (1986) Physical training and insulin sensitivity. Diab Metab Rev 1: 445-481

5. Kemmer FW, Berger M (1986) Therapy and better quality of life: the dichotomous role of exercise in diabetes mellitus. Diab Metab Rev 2: 56-68

6. Horton ES (1988) Role and management of exercise in diabetes mellitus. Diab Care 11:201-211

7. Horton ES, Devlin JT (1989) Exercise and non-insulin-dependent diabetes mellitus. In: Alberti KGMM, Mazze RS (eds) Frontiers in diabetes research: current trends in non-insulin dependent diabetes mellitus. Excerpta medica, Amsterdam New York Oxford, pp 271-284

8. Vranic M, Wasserman D, Bukowiecki L (1990) Metabolic implications of exercise and physical fitness in physiology and diabetes. In: Rifkin H, Porte D (eds) Ellenberg and Rifkin's diabetes mellitus: theory and practice, 4 th edn. Elsevier, New York, pp 198-219

9. Ruderman N, Apelian AZ, Schneider SH (1990) Exercise in therapy and prevention of type II diabetes. Implications for blacks. Diab Care 11 [Suppl 4]: 1163-1168

10. Ruderman NB, Ganda OMP, Johansen K (1979) The effect of physical training on glucose tolerance and plasma lipids in maturity-onset diabetes. Diabetes 28 [Suppl 1]:89-92

11. Barnard RJ, Lattimore L, Holly RG, Cherny S, Pritikin N (1982) Response of non-insulin-dependent diabetic patients to an intensive program of diet and exercise. Diab Care 5:370-374

12. Rönnemaa T, Marniemi J, Puukka P, Kuusi T (1988) Effects of long-term physical exercise on serum lipids, lipoproteins and lipid metabolizing enzymes in type 2 (non-insulin-dependent) diabetic patients. Diab Res 7: 79-84

13. Schneider SH, Ruderman NB (1990) Exercise and NIDDM. Technical review. Diab Care 13: 785-789

14. Skarfors ET, Wegener TA, Lithell H, Selinus I (1987) Physical training as treatment for Type 2 (non-insulin-dependent) diabetes in elderly men. A feasibility study over 2 years. Diabetologia 30: $930-933$

15. WHO Study Group on Diabetes Mellitus (1985) World Health Organization technical report series 727: World Health Organization, Geneva

16. Rose GA, Blackburn H, Gillum RF, Prineas RJ (1982) Cardiovascular survey methods, 2nd edn. World Health Organization, Geneva

17. Uusitupa M (1983) Coronary heart disease and left ventricular performance in newly diagnosed non-insulin-dependent diabetics. Publications of the University of Kuopio. Kuopio: Series original reports $6 / 1983$

18. Durning JVGA, Womersley J (1974) Body fat assessed from total body density and its estimation from skinfold thickness: measurements on 481 men and women aged 16 to 72 years. Br J Nutr 32: 77-97

19. Vanninen E, Uusitupa M, Siitonen O, Laitinen J, Länsimies E, Pyörälä K (1991) Effect of diet therapy on maximum aerobic power in obese, hyperglycaemic men with recently diagnosed type 2 diabetes Scand J Clin Lab Invest 51:289-297

20. Whipp BJ, Davis JA, Torres F, Wasserman K (1981) A test to determine parameters for aerobic function during exercise. J Appl Physiol 50: 217-221

21. Wasserman K (1987) Determinants and detection of anacrobic threshold and consequences of exercise above it. Circulation 76 [Suppl VI]: 29-39

22. Penttilä IM, Voutilainen E, Laitinen O, Juutilainen P (1981) Comparison of different analytical and precipitation methods for the direct estimation of serum high-density lipoprotein cholesterol. Scand J Clin Lab Invest 41:353-360

23. Armitage P (1980) Statistical methods in medical research. Blackwell, Oxford, pp 384-388

24. Hanefeldt M, Fischer S, Schmeckel H, Schultze J, Dude H, Schwanebeck U, Julius U (1991) Diabetes intervention study. Multi-interventional trial in newly diagnosed NIDDM. Diab Care 14: 308-317

25. Fusita Y, Kawaji K, Kanamouri A, Matoba K, Yajima Y, Takeuchi A, Ishii K (1990) Relationship between age-adjusted heart rate and anaerobic threshold in estimating exercise intensity in diabetics. Diab Res Clin Pract 8: 69-74

26. Schneider SH, Amorosa LF, Khachadurian AK, Ruderman NB (1984) Studies on the mechanism of improved glucose control during regular exercise in Type 2 (non-insulin-dependent) diabetes. Diabetologia 26:355-360

27. Trovati M, Carta Q, Cavalot F et al. (1984) Influence of physical training on blood glucose control, glucose tolerance, insulin. secretion, and insulin action in non-insulin-dependent diabetic patients. Diab Care 7: 416-420

28. Rönnemaa T, Mattila K, Lehtonen A, Kallio V (1986) A controlled study on the effect of long-term physical exercise on the metabolic control in type 2 diabetic patients. Acta Med Scand 220: 219-224

29. Uusitupa MIJ, Laakso M, Sarlund H, Majander H, Takala J, Penttilä I (1990) Effects of a very-low-calorie diet on metabolic control and cardiovascular risk factors in the treatment of obese non-insulin-dependent diabetics. Am J Clin Nutr 51: 768-773

30. Wood PD, Stefanik ML, Williams PT, Haskell WL (1991) The effects on plasma lipoproteins of a prudent weight-reducing diet with or without exercise, in overweight men and women. N Engl J Med 325: 461-466

Received: 12 June 1991

and in revised form: 11 November 1991

Dr. E. Vanninen

Department of Clinical Physiology

Kuopio University Hospital

SF-70210 Kuopio

Finland 